\title{
A Wide and Tri-band Flexible Antennas with Independently Controllable Notch Bands for Sub-6-GHz Communication System
}

\author{
Abir ZAIDI ${ }^{1}$, Wahaj Abbas AWAN ${ }^{2}$, Niamat HUSSAIN ${ }^{3}$, Abdennaceur BAGHDAD ${ }^{1}$ \\ ${ }^{1}$ Dept. of Electrical Engineering, Laboratory EEA \& TI, Hassan II University, xStreet 118, Casablanca, Morocco \\ ${ }^{2}$ Dept. of Electrical and Computer Engineering, COMSATS University Islamabad, Sahiwal Campus, Sahiwal, Pakistan \\ ${ }^{3}$ Dept. of Computer and Communication Engineering, Chungbuk National University, Cheongju, Republic of Korea \\ wahajabbasawan@gmail.com, hussain@osp.chungbuk.ac.kr \\ Submitted November 21, 2019 / Accepted February 11, 2020
}

\begin{abstract}
A$ wide-band and tri-band flexible antenna for fifth-generation (5G) sub-6-GHz communication systems is investigated in this paper. The proposed wideband antenna covers the $5 G$ new radio (NR) mid-band, ranging from 2.8 to $5.35 \mathrm{GHz}$, while the tri-band antenna is resonating at three different allocated frequency bands $(2.45 \mathrm{GHz}$, $3.5 \mathrm{GHz}$, and $4.7 \mathrm{GHz}$ ) for $5 \mathrm{G}$ sub-6-GHz communications. This functionality is achieved by introducing hexagonal split-ring resonators in the radiating element, which can be controlled independently without affecting antenna performance to avoid problems of interference in this frequency spectrum. In addition, the antenna also presents a good conformability characteristic, and the simulated results are confirmed with the measurements of the fabricated prototype.
\end{abstract}

\section{Keywords}

Flexible antenna, sub-6-GHz, tri-bands, 5G mid-band, conformal structure

\section{Introduction}

Recently, the advancement of the emerging technologies in wireless communication has caused a superfluous of devices connecting to the internet which cannot be managed by the fourth generation of mobile connectivity [1]. Especially with the elaboration of the concept of internet of things (IoT), that predicts the production of more than 20 billion connected devices to the web in the horizon of 2020 , all of which will claim a connectivity with a ubiquitous coverage and a huge capacity [2]. This is where the fifth generation of communication $(5 \mathrm{G})$ came, for its ability to solve previous mobile generation's issues in term of bandwidth, latency rate, and higher data rate transmission [3]. The 5G technology uses a different frequency spectrum. The first segment is called the low-band spectrum, currently used for previous mobile networks, which in- cludes the frequencies 600,800 , and $900 \mathrm{MHz}$ [4]. This portion is ideal for wide-area, outside-in, and indoor coverage. While the second segment is referred to as the midband or the "sub-6-GHz" portion, characterized by a long wavelength which provides the privilege of traveling long distances along with a great immunity against distortion and the ability to penetrate through buildings [5]. However, it has the disadvantage of having a lower bandwidth and data rate issues.

The last segment is called the millimeter-wave (mmwave) band which will be used in $5 \mathrm{G}$ technology for its promising feature of transmitting a huge amount of data due to its short wavelength [5]. Moreover, mm-wave frequencies are highly distorted from atmospheric conditions and get affected by obstacles [6]. Therefore, using one portion of spectrum over other affects both the speed and the distance of coverage, which incites the $5 \mathrm{G}$ providers to envisage lower-band, mid-band and mm-waves together, to maximize the distance, reduce transmission difficulties and reach the maximal throughput possible. Among the ultimate suitable candidate to ensure the ever-increasing enduser performance requirements, microstrip antennas are widely used due to their low-cost, light-weight, low-profile, and ease of fabrication [7], [8]. Moreover, they are used to produce flexible antennas to be integrated with non-ideal conditions such as bent and twisted surfaces while still maintaining good radiation characteristics [9], [10]. This capability will allow the use of this antenna for future $5 \mathrm{G}$ communications especially in healthcare and medical monitoring by transmitting higher data rates using less expensive stitched or sewed antennas on wearable devices. It will also allow its use for personal communications, such as GSM, WiFi, Bluetooth, etc. [11].

5G antennas have drawn significant attention in the past decade, especially $5 \mathrm{G}$ mid-band antennas, due to limitations of the mm-waves. Since mm-wave devices are expensive to implement and they cover only very short ranges, as well due to the fact that densely populated areas require higher capacities [6]. Therefore, researchers have 
proposed several kinds of antennas for the sub-6-GHz portion of the spectrum, operating at the proposed $5 \mathrm{G}$ frequencies [12-17]. Either these antennas suffer from larger dimension, higher volume, complex structure and rigid substrate which limit their applications for compact and flexible devices. On the hand, a flexible antenna for $5 \mathrm{G}$ communication is reported in [17], however, it still faces the disadvantage of bigger dimension along with no solution is proposed to mitigate the un-wanted sub-bands from the operating region. Moreover, the antennas presented in [12-17] did not cover the entire sub-6-GHz portion, ranging from $2.8-5.2 \mathrm{GHz}$, which has incited researchers to focus on the coverage of the entire $5 \mathrm{G}$ mid-band in order to satisfy end-user requirements.

In addition, multiband $5 \mathrm{G}$ antennas are widely investigated recently by antenna engineers, for their ability to replace multiple antennas by only one multi-band antenna, therefore, enabling multifunctional operations. Many $5 \mathrm{G}$ multi-band antennas have been reported in the literature. In [18], an efficient $5 \mathrm{G}$ antenna covering the frequency ranges from $3.45-3.8 \mathrm{GHz}$ and $5-5.45 \mathrm{GHz}$ is presented, while the provided response from [19] covers the LTE bands $42 / 43$ and 46 ranging respectively from $3.4-3.8 \mathrm{GHz}$ and 5.1-5.9 GHz. Similar work is presented in [20], which proposes a multiband printed planar Inverted-F antenna for $5 \mathrm{G}$ mobile handset. The covered bands by this antenna are ranging from $1.8-2 \mathrm{GHz}$ and $2.3-2.8 \mathrm{GHz}$. From the literature review, it can be deduced that the reported multiband $5 \mathrm{G}$ antennas do not cover all the proposed $5 \mathrm{G}$ midband frequencies by the Federal Communication Commission (FCC), which are $2.5 \mathrm{GHz}, 3.5 \mathrm{GHz}$, and 3.7-4.2 GHz. Therefore, designing an antenna whose frequency can be set accordingly to the end-user indigence is highly required.

Taking into consideration the end-user performance requirements for future $5 \mathrm{G}$ devices, and current deficiencies in state-of-the-art antennas, it may be concluded that designing of a compact size flexible antenna, resonating at all the designated frequency bands for the $5 \mathrm{G}$ new radio (NR) is need of the time to realize the global $5 \mathrm{G}$ communication. Moreover, features like flexibility, independently controllable notch, the capability to suppress unwanted sub-bands, with good responses in term of return loss, bandwidth and radiation characteristics are still challenging for the researchers.

This paper presents a prototype of on-demand wideband to triband frequency switchable flexible antenna for $5 \mathrm{G}$ sub-6-GHz-band communication systems. The presented antenna is capable to exhibit wide-band and tri-band characteristics according to end-user requirements, by controlling independently notch-bands introduced by etching slots in its radiating element. The presented antenna in this manuscript is characterized by a compact size, good return loss, and an acceptable omnidirectional gain, making it a suitable candidate for sub-6-GHz antenna for the future $5 \mathrm{G}$ communications. The rest of the paper is organized in the following sections; Section 2 discusses the antenna topology and design, while Section 3 presents a comparison between simulated and measured results of the proposed antenna, then our work is concluded at the end.

The main contribution of this paper may be summarized as follow:

- To the best of authors' knowledge, it is very first antenna targeting specifically $5 \mathrm{G}$ mid-band applications with on-demand switching ability for wide-band to tri-band characteristics.

- The presented antenna consists of simple geometry which minimizes the fabrication errors with massproduction suitability, while, flexibility analysis proves its stability to be used in flexible devices.

- Moreover, stable radiation pattern, moderate gain and compact size make the presented work a potential candidate for $5 \mathrm{G}$ mid-band applications.

\section{Antenna Topology and Design}

The schematics of the proposed antenna is shown in Fig. 1. The antenna geometry consists of an octagonal patch fed by a Co-Planar Waveguide $(\mathrm{CPW})$, where a stub is introduced along the feedline which significantly enhances the bandwidth of the antenna. Finally, two hexagonal slots were utilized to introduce two notch bands, which can be easily controlled by changing the length of the slots. The conducting part of the antenna is made up of copper having a standard thickness of $0.035 \mathrm{~mm}$, is printed on ultra-thin ROGERS RO4835T $\left(\tan \delta=0.003\right.$ and $\varepsilon_{\mathrm{r}}=$ 3.52) having a thickness of $0.064 \mathrm{~mm}$ [21]. The simulations are carried out in High Frequency Structural Simulator (HFSS) while Microwave CST is used to analyze conformability analysis of the proposed antenna. Optimized

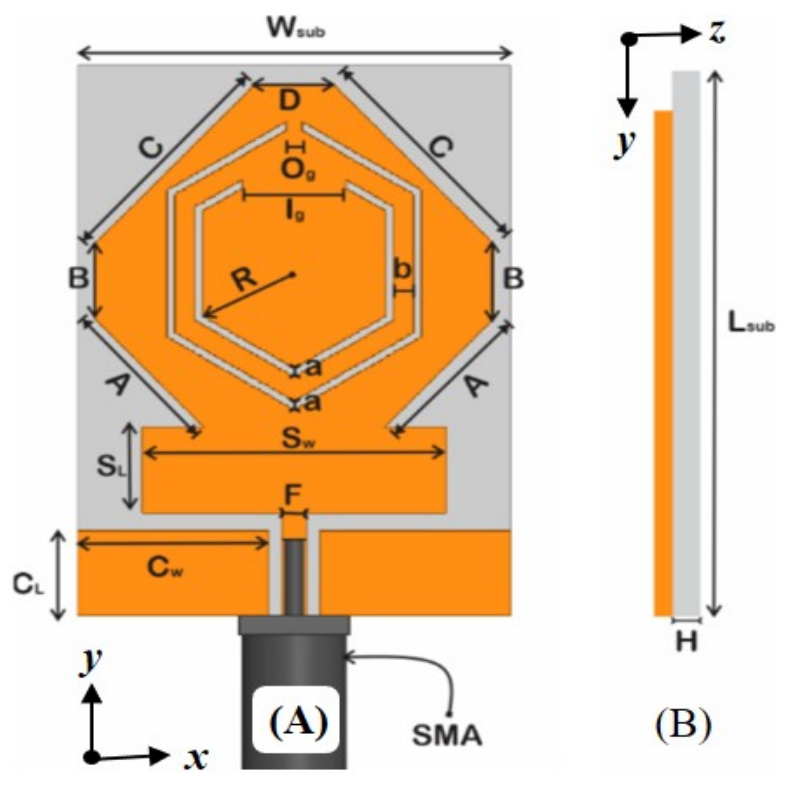

Fig. 1. Geometry of the proposed printed monopole antenna: (A) Front view and (B) side view. 
parameters of the proposed antenna are as follow: $W_{\text {sub }}=$ $25 \mathrm{~mm}, L_{\text {sub }}=32 \mathrm{~mm}, H=0.064 \mathrm{~mm}, C_{1}=5 \mathrm{~mm}, C_{\mathrm{w}}=$ $11 \mathrm{~mm}, S_{\mathrm{L}}=5 \mathrm{~mm}, S_{\mathrm{w}}=17.5 \mathrm{~mm}, F=1.6 \mathrm{~mm}, A=6.3 \mathrm{~mm}$, $B=4.4 \mathrm{~mm}, C=9.1 \mathrm{~mm}, D=4.8 \mathrm{~mm}, O_{\mathrm{g}}=1 \mathrm{~mm}, I_{\mathrm{g}}=$ $6 \mathrm{~mm}, a=0.5 \mathrm{~mm}, b=1.2 \mathrm{~mm}$, and $R=6.1 \mathrm{~mm}$.

\subsection{Design of the Wide-band Antenna}

Initially, a CPW fed octagonal shaped antenna was designed to resonate at $3 \mathrm{GHz}$. The octagonal monopole antenna was extracted from the conventional rectangular monopole antenna whose length $\left(L_{\mathrm{t}}\right)$ can be approximated by using the equation

$$
L_{\mathrm{t}}=\frac{c}{2 f_{\mathrm{n}} \sqrt{1+\frac{\varepsilon_{\mathrm{r}}}{2}}} .
$$

Here $c$ is speed of light, $f_{\mathrm{n}}$ is fundamental resonating frequency, while $\varepsilon_{\mathrm{r}}$ is relative permittivity of the substrate.

Later, the lower and upper edges of rectangular radiator were truncated to further enhance the bandwidth of the antenna. A detailed discussion on effects of truncating ends of patch antenna on bandwidth has been explained briefly in [8]. The resultant antenna shows an impedance bandwidth of $480 \mathrm{MHz}(2.7-3.18 \mathrm{GHz})$. Although the antenna has a compact size of $27 \mathrm{~mm} \times 32 \mathrm{~mm}$ with good performance, still it lags in covering complete $5 \mathrm{G}$ sub-6-GHzband allocated globally. In literature researchers adopted different techniques including fractal geometries [23], insertion of stubs [24], [25], and so on to achieve wideband. Therefore, to further enhance the bandwidth of the antenna a rectangular stub was introduced at the bottom of patch. Thus by tuning the length and width of the stub impedance bandwidth increases more than $100 \%$ as compared to its parent antenna design. In fact, due to insertion of stub the surface charge distribution of radiator gets disturbed and starts supporting multiple resonances unlike the single resonance possessed by octagonal antenna. Thus, required wide bandwidth was achieved by simply insertion of a rectangular stub and can be control by detuning of length and width of the stub. The simulated return loss of the conventional patch antenna and wide-band stub loaded antenna are presented in Fig. 2. It can be seen clearly that octagonal patch has the narrow band as compared to the stub loaded antenna which covers the impedance bandwidth of $2.5 \mathrm{GHz}(2.85-5.35 \mathrm{GHz})$ for $\left|\mathrm{S}_{11}\right|<-10 \mathrm{~dB}$.

\subsection{Design of Tri-band Antenna}

Although a compact size wide-band antenna is designed in the previous section, however, different countries have allocated different band spectrums for $5 \mathrm{G}$ which lies inside this wide-band spectrum. While some other wellknown commercial bands like WiMAX, 4 GHz C-band and others also exist in sub-6-GHz-band. Therefore, to avoid unwanted interference of $5 \mathrm{G}$ communication with other sub-bands, we introduce notch band in the antenna. Slots

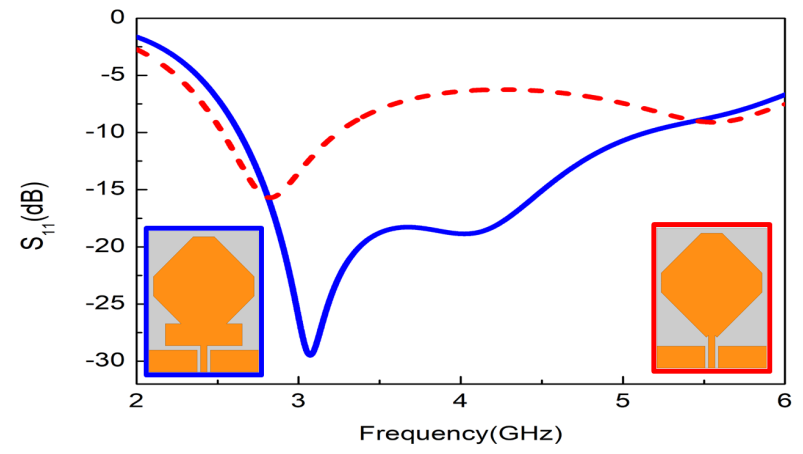

Fig. 2. $\left|S_{11}\right|$ of the conventional antenna and proposed wideband antenna.

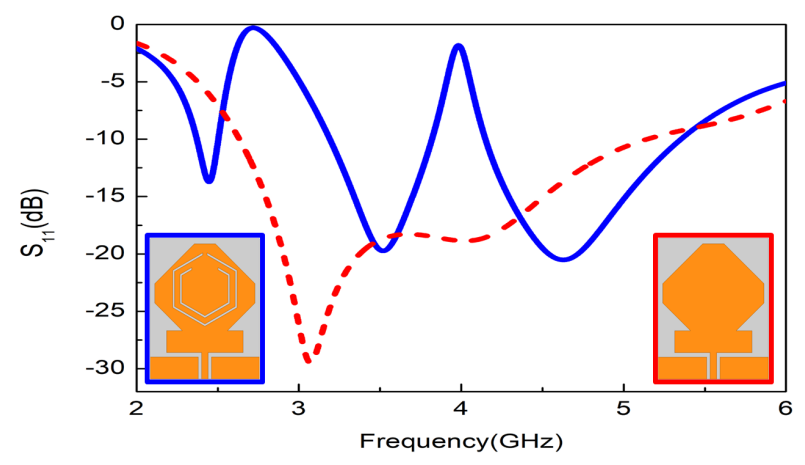

Fig. 3. $\left|\mathrm{S}_{11}\right|$ of the proposed wide-band antenna with the proposed tri-band antenna.

are widely used to achieve notch bands in wide-band antennas, although the placement of the slots at the right position is the biggest challenge for the researchers [24]. Thus, a judicious analysis was carried out in order to identify the correct position of the slot. The length of these slots can be find using the following formula (2):

$$
f_{\text {notch }}=\frac{c_{0}}{2 L_{\text {slot }} \sqrt{\varepsilon_{\mathrm{e}}}}
$$

where $f_{\text {notch }}$ is the central frequency of the slot, $L_{\text {slot }}$ is the total length of the slot, $c_{0}$ is the speed of light in free space and $\varepsilon_{\mathrm{e}}$ is effective dielectric constant and can be calculated by $\left(\varepsilon_{\mathrm{r}}+1\right) / 2$.

The first slot was introduced to mitigate the $4 \mathrm{GHz}$ $\mathrm{C}$-band while the second slot is utilized to stop the interference of Wi-Max band. Depending upon user requirements these notch bands can easily be controlled by changing the dimensions of slots. The simulated $\left|\mathrm{S}_{11}\right|$ for wide-band and the tri-band antenna is depicted in Fig. 3. It can be seen that return loss shows high value in the band-stop region while a low value of $>-20 \mathrm{~dB}$ is observed in band-pass resonance.

\subsection{Independently Controllable Notch Bands}

Since the past decade, on-demand frequency switchable antennas with independently controllable notch bands gain considerable attention due to ease of controlling notch bands according to user requirements [24]. The flexible antennas having the functionality of independently con- 
trollable notch bands are suitable for modern flexible devices. Thus, the wide-band antenna presented in Sec. 2.1 is converted into a tri-band antenna in Sec. 2.2 in such a way that the individual notch bands can be controlled easily without effecting the other bands. Figure 4 presents the parametric analysis of the slots. It can be seen from Fig. 4(A) that changing the value $I_{\mathrm{g}}$ only affects the resonance of the second notch band, while the first notch band remains unchanged. A similar phenomenon is observed in Fig. 4(B) when we change the value of $O_{\mathrm{g}}$. The effect of these slots can better be analyzed by using surface current $\left(J_{\text {surf }}\right)$ distribution at the notch bands, as shown in Fig. 5. It can be seen that the maximum current density at $2.6 \mathrm{GHz}$ is concentrated across the outer slot (Fig. 5(A)), which is responsible to mitigate the lower band. Similarly, as shown in Fig. 5(B), the maximum current density at $4 \mathrm{GHz}$ is across the inner slot in case of lower notch band, which is responsible for the notching behavior in the upper band. In both cases, the current density is concentrated around one

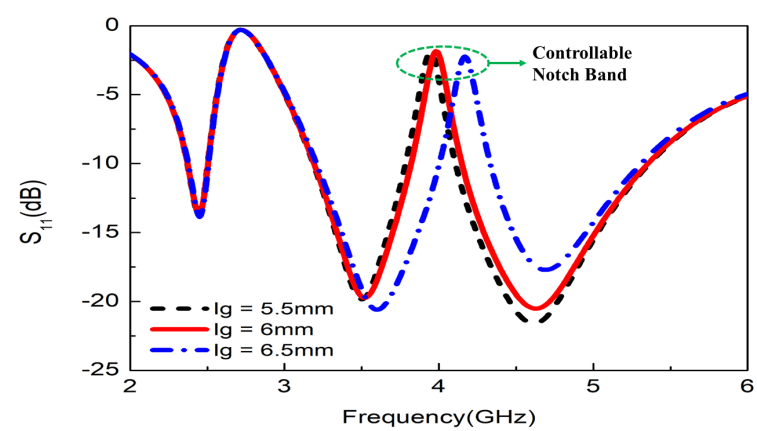

(A)

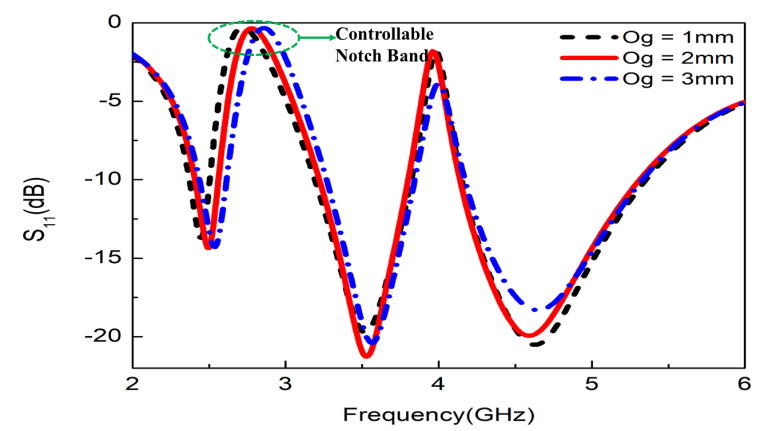

(B)

Fig. 4. Parametric analysis of the length of the slot to independently control (A) upper notch band and (B) lower notch band.

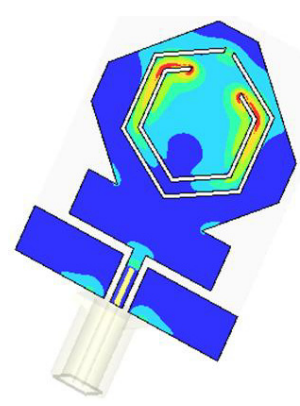

(A)
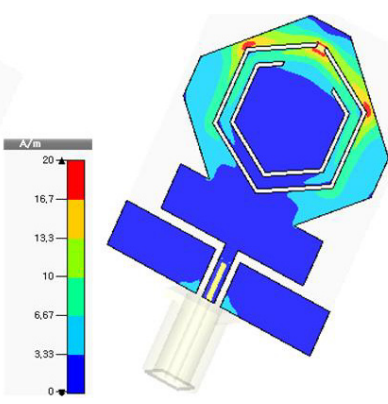

(B)
Fig. 5. Surface current $\left(J_{\text {surf }}\right)$ of the proposed tri-band antenna at (A) $2.6 \mathrm{GHz}$ and (B) $4 \mathrm{GHz}$. slot while the other slot has a negligible current, which enables the easy and independently controlling of the passband and the rejection band.

\section{Result and Discussion}

In order to demonstrate the validity of the proposed antenna for $5 \mathrm{G}$ mid-band applications, a prototype of the proposed antenna is fabricated and measured.

\subsection{Return Loss}

Figure 6(A) presents simulated and measured return loss results of the wide-band antenna without notching characteristics. It is clearly shown from the plot that simulated and measured results are in good agreement. Both simulated and measured antennas are covering the same bandwidth, ranging from 2.85 to $5.35 \mathrm{GHz}$, i.e. $50 \%$ of FBW, with a minimum reflection coefficient equal to $-28.58 \mathrm{~dB}$. On the other hand, Figure 6(B) shows both simulated and measured return loss response of the proposed antenna with notching characteristics. The simulated results agree well with the measured results. The antenna rejects two on-demand frequency bands, that is from 2.5-3 GHz and 3.9-4.1 GHz. Therefore, the proposed antenna is resonating at three different operating frequencies, which are $2.45,3.5$, and $4.7 \mathrm{GHz}$, with return loss coefficients equal to $-15 \mathrm{~dB},-19 \mathrm{~dB}$, and $-22 \mathrm{~dB}$, respectively. It is worth noting that these pass-bands cover the frequency bands allocated for $5 \mathrm{G}$ NR at sub-6-GHz.

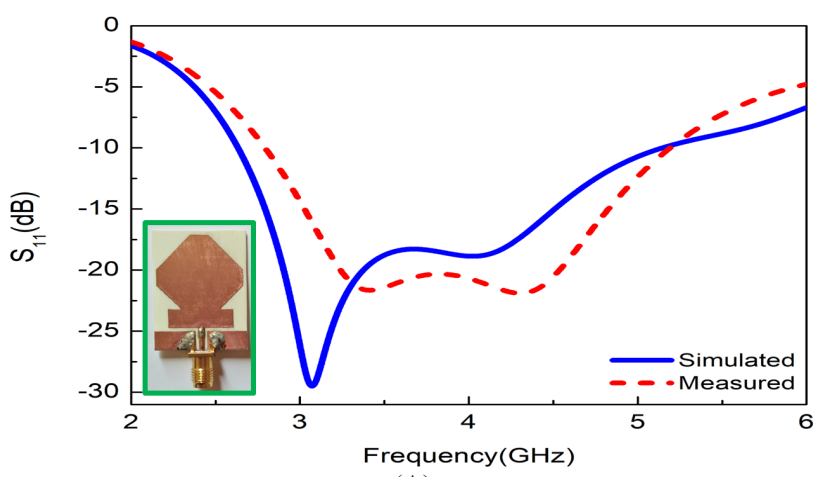

(A)

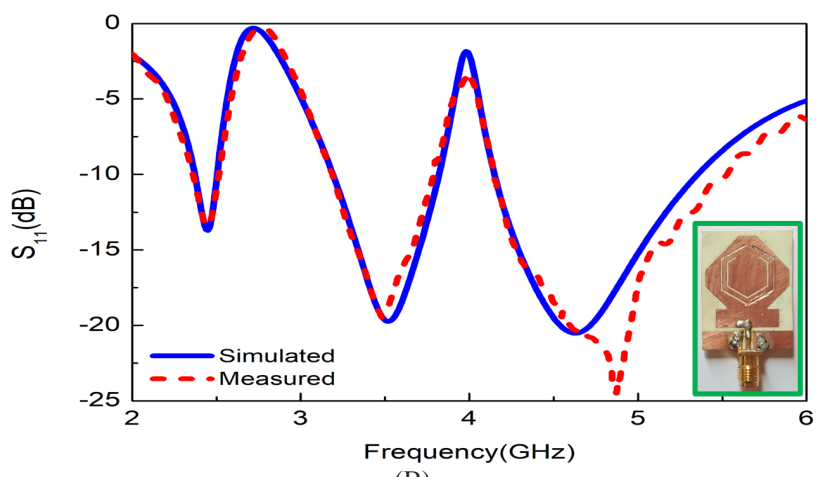

(B)

Fig. 6. Return loss comparison: (A) wide-band antenna and (B) tri-band antenna. 


\subsection{Peak Gain}

The realized peak gain of the proposed antenna, which describes the input power concentration in the main beam direction is investigated in Fig. 7. The simulated and measured peak gain results of the proposed antenna without notching characteristics are plotted in Fig. 7(A). The gain increases from $2.5 \mathrm{dBi}$ to $3.75 \mathrm{dBi}$ all along the covered spectrum demonstrating a good agreement between the simulated and its counterpart. However, the gain of the tri-band antenna (Fig. 7(B)) reduces to negative values exactly at the cut-off frequencies that we are aiming to reject, while shows the stable and moderate gain levels at the pass-bands.

\subsection{Radiation Pattern}

Figure $8(\mathrm{~A}-\mathrm{F})$ presents simulated and measured radiation pattern plots of both wide-band and triband antenna, in $E$-plane $\left(\phi=0^{\circ}\right)$ and $H$-plane $\left(\phi=90^{\circ}\right)$. The wide-band antenna exhibits an omnidirectional radiation pattern in $E$-plane along with a bidirectional radiation pattern in the $H$-plane at all the investigated frequencies $(3.5,4.2$, and $4.6 \mathrm{GHz})$ as shown in Fig. $8(\mathrm{~A}-\mathrm{C})$, which proves the stability of the proposed antenna over the entire band. Moreover, a good agreement between simulated and measured results is noticed. The same observations are noticed for the tri-band antenna as depicted in Fig. 8(D-F), demonstrating the identical radiation patterns at the desired frequency bands.

\subsection{Conformability Analysis}

In this section, we carried out conformability tests on the proposed wide-band and tri-band antenna to validate

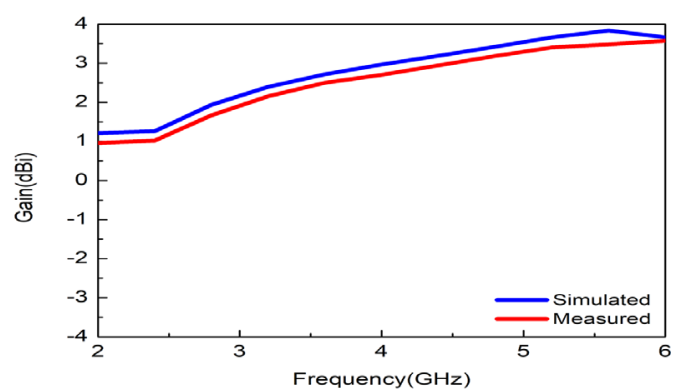

(A)

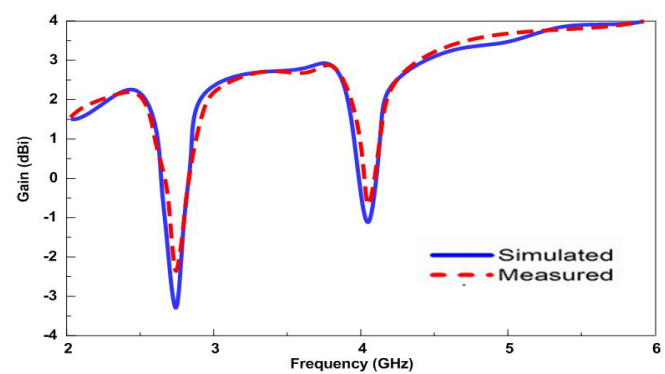

(B)

Fig. 7. Realized peak gain vs. frequency plot comparisons of (A) wide-band antenna and (B) tri-band antenna.

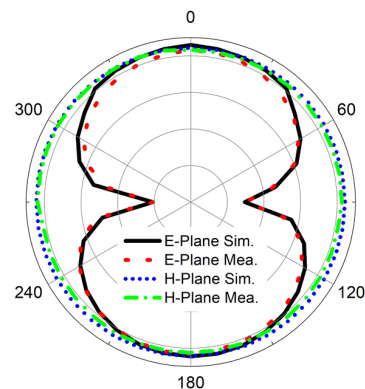

(A)

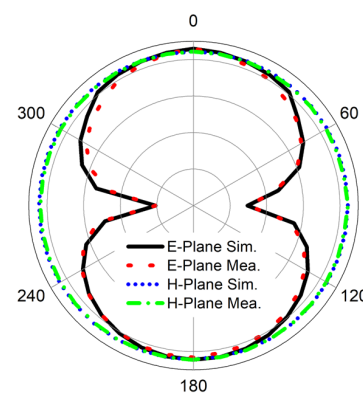

(C)

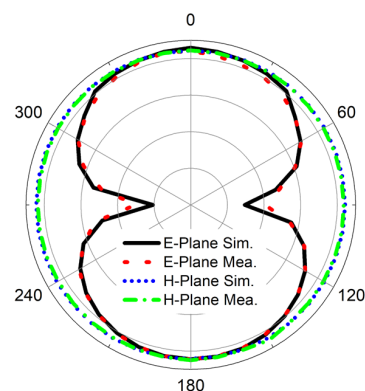

(E)

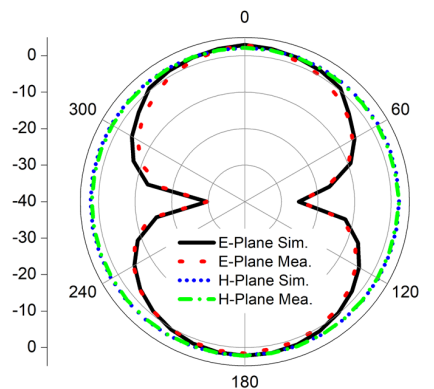

(B)

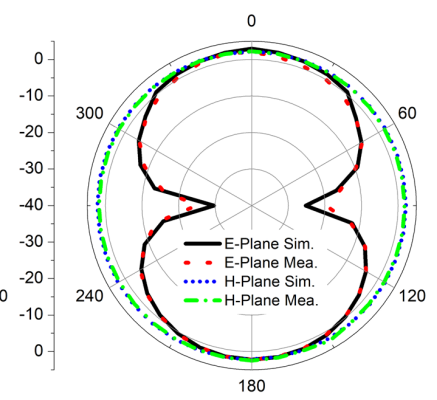

(D)

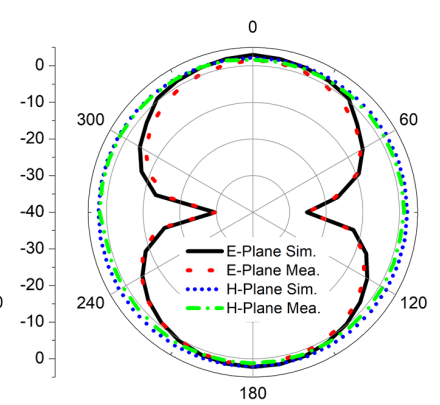

(F)
Fig. 8. Comparison of simulated and measured radiation patterns of wide-band antenna [(A) $3.3 \mathrm{GHz}$, (B) $3.5 \mathrm{GHz}$, (C) $3.7 \mathrm{GHz}$ ] and tri-band antenna [(D) $2.5 \mathrm{GHz}$, (E) $3.5 \mathrm{GHz},(\mathrm{F}) 4.6 \mathrm{GHz}$.

their flexibility. To do so, the ultra-thin antenna is bent for the various radii $(S)$ of the cylinder. For measurement purposes, styrofoam of various radius is used, while the antenna is wrapped around it. The measured results and their comparison with simulated ones are presented. Figure 9 shows the conformability analysis comparison between simulated and measured results of the antennas. A good agreement between simulated and measured results is observed for the wide-band antenna as well as the tri-band antenna. It can be seen that the antennas have a negligible effect on the return loss for various bending radius. A similar phenomenon is also observed in the reported antennas [25]. Thus, it can be concluded that the proposed antenna can be used in flexible devices without deteriorating its performance.

\subsection{Comparison with State-of-the-Art Works}

Table 1 presents a comparison of the proposed antenna with similar state-of-the-art works [12, 13, 17-19, 26, 27]. It can be seen that this design has a miniaturized size compared to the designs presented at $[12,13,17,18,26,27]$, 


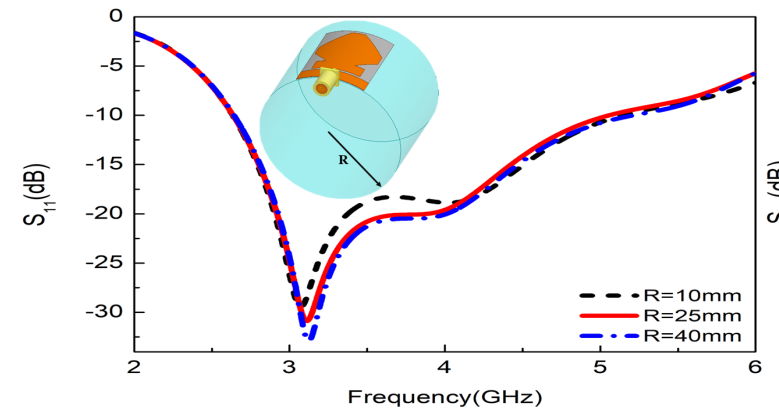

(A)

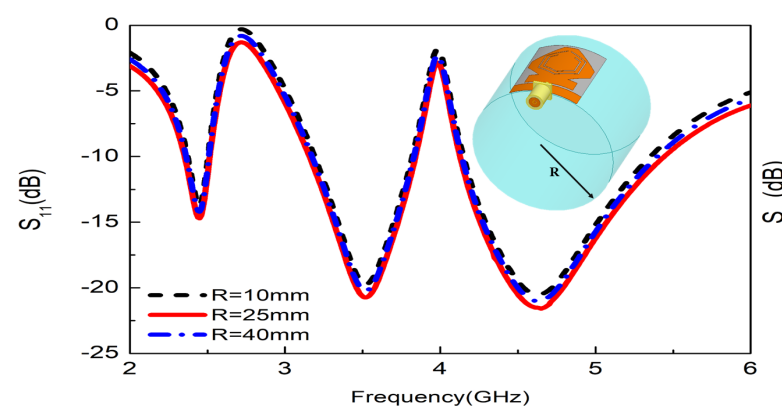

(C)

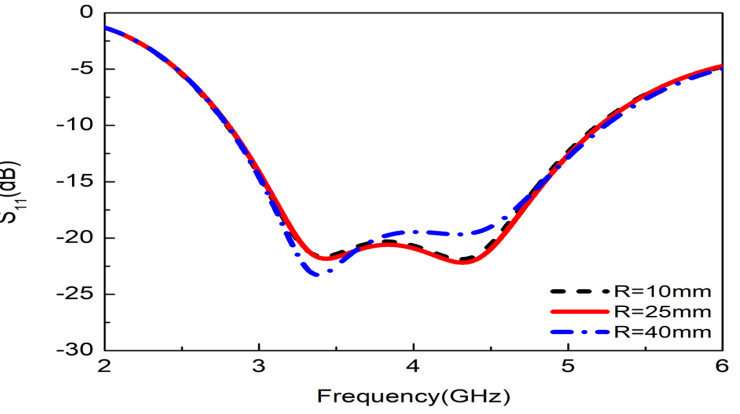

(B)

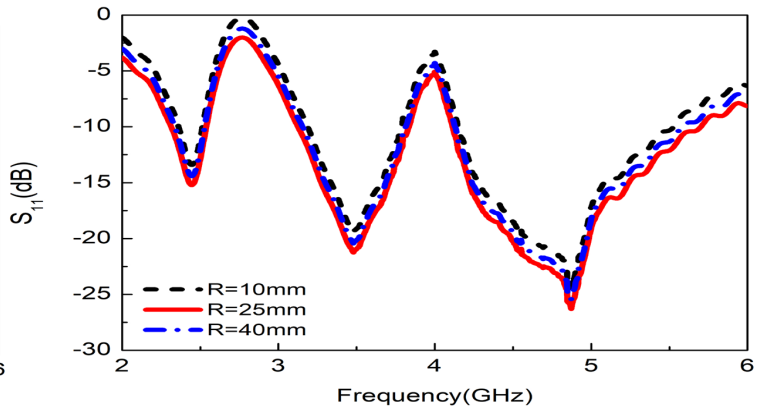

(D)

Fig. 9. Performance analysis of the conformal wide-band antenna [(A) simulated, (B) measured] and tri-band antenna[(C) simulated, (D) measured].

\begin{tabular}{|c|c|c|c|c|c|}
\hline Sr. No. & $\begin{array}{c}\text { Dimension } \\
\left(\mathrm{mm}^{2}\right)\end{array}$ & Operation Mode & $\begin{array}{c}\text { Bandwidth } \\
\text { (GHz) }\end{array}$ & $\begin{array}{c}\text { Peak Gain } \\
\text { (dBi) }\end{array}$ & Flexibility \\
\hline$[12]$ & $70 \times 70$ & single-band & $3.14-3.83$ & 8.6 & No \\
\hline [13] & $200 \times 200$ & single-band & $1.71-2.83$ & $>8$ & No \\
\hline [17] & $60 \times 75$ & single-band & $7-13$ & 5 & Yes \\
\hline [18] & $35 \times 53$ & $\begin{array}{l}\text { single-band } \\
\text { dual-band }\end{array}$ & $\begin{array}{c}3.4-4.2 \\
2.3-2.5 / 5.2-5.5\end{array}$ & $\begin{array}{c}2.5 \\
1.7 / 3.4\end{array}$ & No \\
\hline [19] & $23 \times 31$ & $\begin{array}{l}\text { single-band } \\
\text { dual-band }\end{array}$ & $\begin{array}{c}2.8-4.5 \\
2.7-4.2 / 6-7.2\end{array}$ & $\begin{array}{c}4.01 \\
4.60 / 4.6\end{array}$ & No \\
\hline$[26]$ & $30 \times 60$ & dual-band & $2.52-2.62 / 3.31-3.64$ & $2.39 / 1.75$ & Yes \\
\hline [27] & $31 \times 59$ & $\begin{array}{l}\text { single-band } \\
\text { dual-band }\end{array}$ & $\begin{array}{c}2.34-2.5 \\
2.27-2.45 / 3.5-3.77\end{array}$ & $\begin{array}{c}1 \\
0.7 / 0.79\end{array}$ & Yes \\
\hline $\begin{array}{c}\text { This } \\
\text { Work }\end{array}$ & $25 \times 32$ & $\begin{array}{l}\text { single-band } \\
\text { tri-band }\end{array}$ & $\begin{array}{c}2.85-5.35 \\
2.35-2.5 / 3.18-3.82 / 4.15-5.42\end{array}$ & $\begin{array}{c}3.75 \\
2.1 / 2.8 / 3.5\end{array}$ & Yes \\
\hline
\end{tabular}

Tab. 1. Performance comparison of the proposed antenna with other state-of-the-art works in literature.

having the additional functionalities of structural conformability and frequency switching capability. Although the antenna reported in [19] offers the advantages of compact size, it has a setback of a rigid body which limits its usage in modern flexible devices. Moreover, no solution is proposed to mitigate the specific band from $5 \mathrm{G}$ mid-band spectrum. In conclusion, the proposed antenna, characterized by a stable gain, frequency switching, structural flexibility, and independently controllable notch band can be considered as a potential candidate for both rigid and flexible devices operating in $5 \mathrm{G}$ sub-6-GHz band spectrum.

\section{Conclusion}

A flexible wide-band to tri-band frequency switchable antennas with independently controllable notch bands for $5 \mathrm{G}$ sub-6-GHz communication systems is presented. A wide impedance bandwidth is achieved using a stub, while slots were utilized to achieve two independently controllable notch bands. Moreover, a good agreement between the simulated and measured results validates our findings. The properties like compact size, conformability, stable gain, omnidirectional radiation pattern, and independently controllable notch bands make it a potential candidate for the $5 \mathrm{G}$ mid-band applications.

\section{References}

[1] ANDREWS, J. G., BUZZI, S., CHOI, W., et al. What will 5G be? IEEE Journal on Selected Areas in Communications, 2014, vol. 32, no. 6, p. 1065-1082. DOI: 10.1109/JSAC.2014.2328098

[2] REBHI, S., BARRAK, R., MENIF, M. Flexible and scalable radio over fiber architecture. Radioengineering, 2019, vol. 28, no. 2, p. 357-368. DOI: $10.13164 /$ re.2019.0357 
[3] RAPPAPORT, T. S., SUN, S., MAYZUS, R., et al. Millimeter wave mobile communications for $5 \mathrm{G}$ cellular: It will work! IEEE Access, 2013, vol. 1, p. 335-349. DOI: 10.1109/ACCESS.2013.2260813

[4] Dehos, C., GONZÁlez, J. L., DE DOMENiCO, A., et al. Millimeter-wave access and backhauling: The solution to the exponential data traffic increase in $5 \mathrm{G}$ mobile communications systems? IEEE Communications Magazine, 2014, vol. 52, no. 9, p. 88-95. DOI: 10.1109/MCOM.2014.6894457

[5] ROH, W., SEOL, J. Y., PARK, J., et al. Millimeter-wave beamforming as an enabling technology for $5 \mathrm{G}$ cellular communications: Theoretical feasibility and prototype results. IEEE Communications Magazine, 2014, vol. 52, no. 2, p. 106-113. DOI: 10.1109/MCOM.2014.6736750

[6] RAPPAPORT, T. S., MURDOCK, J. N., GUTIERREZ, F. State of the art in $60-\mathrm{GHz}$ integrated circuits and systems for wireless communications. Proceedings of the IEEE, 2011, vol. 99, no. 8, p. 1390-1436. DOI: 10.1109/JPROC.2011.2143650

[7] AKHTAR, F., NAQVI, S. I., ARSHAD, F., et al. A flexible and compact semicircular antenna for multiple wireless communication applications. Radioengineering, 2018, vol. 27, no. 3, p. 671-678. DOI: $10.13164 / \mathrm{re} .2018 .0671$

[8] HUSSAIN, N., JEONG, M. J., PARK, J., et al. A broadband circularly polarized Fabry-Perot resonant antenna using a singlelayered PRS for 5G MIMO applications. IEEE Access, 2019, vol. 7, p. 42897-42907. DOI: 10.1109/ACCESS.2019.2908441

[9] JAYASINGHE, J., ANGUERA, J., UDUWAWALA, D. Genetic algorithm optimization of a high-directivity microstrip patch antenna having a rectangular profile. Radioengineering, 2013, vol. 22 , no. 3, p. 700-707. ISSN: 1210-2512

[10] JAYASINGHE, J., UDUWAWALA, D. N., ANGUERA, J. Design of a genetic microstrip patch antenna with broadside radiation for GSM applications. International Journal of Scientific World, 2014, vol. 2, no. 2, p. 84-87. DOI: 10.14419/ijsw.v2i2.3703

[11] AWAN, W. A., ZAIDI, A., HUSSAIN, N., et al. Compact size Yshaped broadband antenna for E-band applications. In IEEE International Conference on Wireless Technologies, Embedded and Intelligent Systems (WITS). Fez (Morrocco), 2019, p. 1-3. DOI: 10.1109/WITS.2019.8723799

[12] HUSSAIN, N., AZIMOV, U., PARK, J. W., et al. A microstrip patch antenna sandwiched between a ground plane and a metasurface for WiMAX applications. In Asia-Pacific Microwave Conference (APMC). Kyoto (Japan), 2018, p. 1016-1018. DOI: 10.23919/APMC.2018.8617342

[13] SARKAR, D., SRIVASTAVA, K. V., SAURAV, K. A compact microstrip-fed triple band-notched UWB monopole antenna. IEEE Antennas Wireless Propagation Letters, 2014, vol. 13, p. 396-399. DOI: 10.1109/LAWP.2014.2306812

[14] BONG, H.-U., HUSSAIN, N., RHEE, S.-Y., et al. Design of an UWB antenna with two slits for 5G /WLAN-notched bands. Microwave and Optical Technology Letters, 2019, vol. 61, no. 5, p. 1295-1300. DOI: $10.1002 /$ mop.31670

[15] CHU, Q. X., YANG, Y. Y. A compact ultrawideband antenna with 3.4/5.5 GHz dual band-notched characteristics. IEEE Transactions on Antennas and Propagation, 2008, vol. 56, no. 12, p. 3637-3644. DOI: 10.1109/TAP.2008.2007368

[16] GHIMIRE, J., CHOI, D. Y. Design of a compact ultrawideband Ushaped slot etched on a circular patch antenna with notch band characteristics for ultrawideband applications. International Journal of Antennas and Propagation, 2019, p. 1-10. DOI: $10.1155 / 2019 / 8090936$

[17] TIGHEZZA, M., RAHIM, S. K. A., ISLAM, M. T. Flexible wideband antenna for $5 \mathrm{G}$ applications. Microwave and Optical
Technology Letters, 2018, vol. 60, no. 1, p. 38-44. DOI: 10.1002/mop.30906

[18] ULLAH, S., HAYAT, S., UMAR, A., et al. Design, fabrication and measurement of triple band frequency reconfigurable antennas for portable wireless communications. AEU-International Journal of Electronics and Communications, 2017, vol. 81, p. 236-242. DOI: $10.1016 /$ j.aeue.2017.07.028

[19] IQBAL, A., SMIDA, A., MALLAT, N. K., et al. Frequency and pattern reconfigurable antenna for emerging wireless communication systems. Electronics, 2019, vol. 8, no. 4, p. 1-12. DOI: $10.3390 /$ electronics 8040407

[20] CHATTHA, H. T., HANIF, M., YANG, X., et al. Frequency reconfigurable patch antenna for $4 \mathrm{G}$ LTE applications. Progress in Electromagnetics Research M, 2018, vol. 69, p. 1-13. DOI: 10.2528/PIERM18022101

[21] ROGERS CORPORATION. [Online] Cited August 2019. Available at: www.rogerscorp.com.

[22] AWAN, W. A., ZAIDI, A., BAGHDAD, A. Super wide band miniaturized patch antenna design for $5 \mathrm{G}$ communications. In International Conference on Wireless Technologies, Embedded and Intelligent Systems (WITS). Fez (Morrocco), 2019, p. 1-2. DOI: 10.1109/WITS.2019.8723762

[23] AWAN, W. A., HUSSAIN, N., LE, T. T. Ultra-thin flexible fractal antenna for $2.45 \mathrm{GHz}$ application with wideband harmonic rejection. AEU-International Journal of Electronics and Communication, 2019, vol. 101, p. 1-7. DOI: 10.1016/j.aeue.2019.152851

[24] AWAN, W. A., ZAIDI, A., HUSSAIN, N., et al. Stub loaded, low profile UWB antenna with independently controllable notch bands. Microwave and Optical Technology Letters, 2019, vol. 61, no. 11, p. 2447-2454. DOI: $10.1002 / \mathrm{mop} .31915$

[25] ARIF, A., ZUBAIR, M., ALI, M., et al. A compact, low-profile fractal antenna for wearable on-body WBAN applications. IEEE Antennas and Wireless Propagation Letters, 2019, vol. 18, no. 5, p. 981-985. DOI: 10.1109/LAWP.2019.2906829

[26] DATTATREYA, G., NAIK, K. K. A low volume flexible CPWfed elliptical-ring with split-triangular patch dual-band antenna. International Journal of $R F$ and Microwave Computer-Aided Engineering, 2019, vol. 29, no. 8, p. 1-9. DOI: 10.1002/mmce. 21766

[27] SAEED, S. M., BALANIS, C. A., BIRTCHER, C. R. Inkjetprinted flexible reconfigurable antenna for conformal WLAN/WiMAX wireless devices. IEEE Antennas and Wireless Propagation Letters, 2016, vol. 15, p. 1979-1982. DOI: 10.1109/LAWP.2016.2547338

\section{About the Authors ...}

Abir ZAIDI got her Ph.D. degree from Hassan II University, Mohammedia-Casablanca, Morocco. Her works studies and interests are focused on the design of the multiband microstrip patch antennas to operate in the $5 \mathrm{G}$ and millimeter wave band.

Wahaj Abbas AWAN (corresponding author) received his B.S. degree in Electrical and Computer Engineering from COMSATS University Islamabad, Sahiwal Campus, Pakistan, in 2018. He is author and co-author of more than 10 international conference papers and reputed journal papers. His research interests include electrically small reconfigurable antenna design. 
Niamat HUSSAIN (corresponding author) got his B.S. degree in Electronics Engineering from Dawood University of Engineering and Technology, Karachi, Pakistan, in 2014 and did his M.S in Electrical and Computer Engineering at Ajou University, Suwon, Korea. He is currently pursuing his $\mathrm{Ph} . \mathrm{D}$. in Information and Communication Engineering at Chungbuk National University, Chungju-si, Korea. He was bestowed with best paper award on 2017, for his presented paper at Korea Winter Conference. His research is mainly focused on lens-coupled antennas, meta- surface antennas, metamaterial antennas, UWB antennas, mm-wave antennas and terahertz antennas.

Abdennaceur BAGHDAD is a University Professor (PES) at the University Hassan II Mohammedia CasablancaMorocco (FSTM). He is a member of the laboratory EEA\&TI (Electonics, Energy, Automatic and Information Processing). The research works of A. Baghdad concern the communication and information technology. He supervises doctoral theses and he is a coauthor of several national and international publications. 